\title{
Las calles: (des)movilización ciudadana en Quito (2015 - 2019). Una perspectiva comparada de los movimientos populares de indignación.
}

\section{The streets: citizens'(de)mobilization in Quito (2015 - 2019). A comparative perspective popular movements of the indignation}

Carlos de Domingo Soler

Recepción: 23 de septiembre de 2019

Aceptación: 14 de octubre de 2019

\section{Resumen}

Durante las dos últimas décadas, el pueblo ecuatoriano se ha enorgullecido de su histórica capacidad para derrocar gobiernos impopulares, cuyo clímax cívico se vivió en 2005, con la llamada Rebelión de los Forajidos y la caída del régimen de Lucio Gutiérrez. La presente investigación, realizada bajo el prisma de la observación participante, pretende analizar el cambio de paradigma de la protesta social en las postrimerías del correísmo hasta las Elecciones Seccionales de 2019. En este texto defendemos que, al contrario de lo ocurrido en las últimas revoluciones situadas a lo largo del orbe, las redes sociales jugaron un papel esencialmente negativo en el contexto ecuatoriano, de desmovilización social, mismo que no supo ser reconducido por los agentes políticos de oposición.

Palabras clave. Militancia política, movilización social, performatividad, redes sociales.

Abstract. During the last two decades, Ecuadorians have prided themselves on their historic capacity to overthrow unpopular governments, whose civic climax was lived in 2005, with the so-called Rebellion of the Outlaws -"Forajidos"- and the fall of Lucio Gutiérrez's regime. The present investigation, carried out using participant observation, tries to analyze the change of paradigm of the protest forms and the social mobilization at the end of the Correismo until the sectional elections of 2019. In this text, we argue that, contrary to what happened in the last revolutions located along the globe, social networks played and essentially negative role in the Ecuadorian context causing social demobilization, which could not be then redirected by the political agents of opposition.

Keywords. Political militancy, social mobilization, performativity, social networks. 


\section{Introducción}

lo largo de la historia contemporánea, la ocupación de espacios públicos ha sido contemplada como uno de los principales símbolos 1 de expresión popular, tanto de celebración colectiva como de indignación social. Como fuerza performativa del descontento, la ocupación de espacios públicos ha supuesto y representado la caída de regímenes y la potencial toma de poder de las categorías contrahegemónicas. Alrededor del orbe, las calles -entendidas como la conjunción difusa de distintos reclamos populares-son regadas a diario con la presencia de numerosas expresiones sociales y políticas reivindicativas.

Históricamente, salir a las calles se ha convertido en el más elemental -primario, contestatario, visual- medio de protesta. También, es innegable el poder simbólico que surge del enlace de un discurso político con un espacio público. Éste otorga cierto valor tangible al discurso, lo hace más táctil, lo imprime en la retina generacional y otorga un escenario evocatorio en el imaginario colectivo, lo provee de una imagen fundamental y un marco espacial mediático, rescatándolo de la abstracción ideológica.

Ahora bien, ¿aún mantienen las calles el mismo protagonismo?, ¿siguen siendo el principal medio de protesta política -bien diferenciada de disturbios y expresiones violentas-? O, más bien, ¿han quedado relegadas frente a la creciente incidencia política de las redes sociales? Como sostengo en el presente texto, la protesta ciudadana y la militancia política se desmovilizó paulatinamente desde las postrimerías del correísmo, enfrentándonos, ya en 2019, con unas Elecciones Seccionales con escasa presencia real-performativa, creativa, discursiva- en las calles, más allá de los excesos visuales y espaciales de la propaganda de plástico.

\section{Metodología: observación participante.}

Entre los años 2015 y 2017 pude conocer, de primera mano, la comunicación política y el marketing electoral desplegado por determinados agentes políticos, sus movilizaciones, dinámicas de comunicación interna y, dicho sea de paso, el 
palpable descontento de la base militante -de mayoría no inscrita en el Consejo Nacional Electoral como miembro de alguna organización política-. También pude observar numerosos plantones y marchas a lo largo de la geografía urbana de Quito, siendo testigo de la paulatina desmovilización que la protesta popular vivió desde las marchas de junio de 2015 hasta el ocaso correísta, tendencia de desmovilización a la que, recientemente -y aun habiéndose modificado las fricciones de la coyuntura nacional que vivió el Ecuador hasta 2017-, pudimos asistir durante las Elecciones Seccionales de 2019.

Desde 2017 hasta la actualidad no he tenido ninguna participación profesional con agente o movimiento político alguno. No obstante, sí mantuve contacto constante con candidatos a distintas dignidades -desde alcaldías y concejalías, hasta prefecturas y presidencias parroquiales-, sus equipos de comunicación y sus gerentes de campaña. De este modo, pude conocer a grosso modo las preocupaciones existentes en algunas campañas acerca de la movilización de la ciudadanía, la confección del discurso y el uso de las redes sociales.

\section{Poder evocatorio. Hegemonía del espacio.}

Los fenómenos de la vida en sociedad están inherentemente vinculados a los espacios públicos donde se han desarrollado (Proshansky, et al. 1983: 57). La unión entre praxis y el ámbito espacial donde tiene lugar crea un binomio performativo forma-fondo que los liga entre sí, surgiendo un trasfondo evocatorio de significación colectiva. Precisamente, es dicha unión -entre el fondo discursivo del performance y su forma de expresión física y espacialla que posibilita su uso simbólico y su intenso poder evocatorio.

De este modo, surge una controvertida categoría de poder en términos foucaulteanos, que no depende directamente de la obediencia debida al soberano y su autoridad. En todo caso, podría ser más conveniente hablar de obediencia desde la teoría gramsciana.

El poder evocatorio revela y supone auténtico poder en la conciencia de los sujetos, como régimen decisor de lo posible y lo imposible. Es el poder 
del recuerdo, de la memoria y del olvido - nociones que, durante esta década y su predecesora, vivieron un notable desarrollo jurídico-. Es un poder operativo, práctico y performativo: es el poder de la acción de recordar, de olvidar, de reconocerse como sujeto - ¿hablaríamos, pues, de una forma de subjetivación?-, de reencontrarse en/con el mito. Sin embargo, es un poder cuya coactividad es difícil de ubicar y demostrar, ya que, aparentemente, ningún dispositivo o aparato está presente en él, con la única excepción de la evocación en sí misma. Ciertamente, es un poder cultural, sistémico y estructural, ¿pero hasta qué punto real, positivo, coactivo o jurídico?

El poder de evocación aflora y retiene en el imaginario colectivo toda significación política-experiencial, no solo del espacio -que se articula/ desarticula hegemónicamente-, sino de la propia Historia. Reafirma las narrativas políticas, aviva y refunda las voluntades y los deseos de los individuos. Si acorde al pensamiento marxista, somos seres históricos no solo en sentido lógico-consecuencial, sino de nuestra inserción en el devenir histórico, constituido de pasado, presente y futuro-, ¿qué sentido tiene nuestra historicidad si, precisamente, prescindimos de la evocación de aquellos hechos que, habiendo acontecido en el pasado, configuran nuestro presente y nuestro futuro?

Así, espacio y experiencia se condensan. Lo acontecido, pues, se disuelve en un binomio único dotado de forma y fondo. Hablamos de un recuerdo, una historia, una sensación, un odio y un miedo, un lugar, un amor, un escenario experiencial. El espacio, y en esto asumo el riesgo de caer en reduccionismos, es el lienzo del basto mundo de lo empírico. Adoptemos una perspectiva ontológica, el espacio es narrativamente indispensable, habida cuenta que toda narrativa necesita del factor espacial como requisito y fuente de su propia contextualización. El espacio, como recurso físico consagrado a los acontecimientos que en él tuvieron lugar, permite el tacto simbólico, la transmutación de lo abstracto a lo real, del simple recuerdo al redescubrimiento de lo sensacional.

Encontramos numerosos hitos históricos que, sin el marco de los espacios públicos donde tuvieron lugar, perderían entidad simbólica y representativa en la memoria colectiva, así como su significación tangible. 
Siguiendo levemente la teoría del marco de Lakoff, difícilmente podemos pensar en la Revolución Francesa sin el recuerdo de La Bastille -como espacio, como fortaleza y prisión, como monumento emblemático del Ancien Régime-. Tampoco en la lucha por los derechos civiles en Estados Unidos sin la caminata de Selma a Montgomery -como performance, con el estado de Alabama como escenario-, en la opresión del régimen chino sin la represión de los estudiantes manifestantes de la Plaza de Tiananmén -como performance y escenario, como fotografía-texto inmortal ${ }^{1}$-, la lucha de las madres de los desaparecidos argentinos sin la Plaza de Mayo, la revolución egipcia de 2011 sin la Plaza Tahrir -escenario identificativo de la revolución de 1952-, los indignados españoles sin la Puerta del Sol${ }^{2}$-imprescindible para comprender las actuales pulsiones sociopolíticas de España-, la victoria electoral de Syriza en 2015 sin la Plaza Syntagma, o el movimiento Occupy sin el trasfondo -físico y simbólico- de Wall Street como epicentro escénico de la narrativa de la opresión financiera del capitalismo, el imperialismo y el corporativismo.

Eliminando de la ecuación los marcos físicos -referenciales, representativos, gráficos- de los acontecimientos históricos mencionados, ¿qué recurso evocatorio y simbólico quedaría en su lugar? Difícilmente pensamos en un hecho histórico en abstracto. Dependemos de cuadros, lugares, monumentos, fotografías y recreaciones cinematográficas -aun siendo moderna, conocemos la barbarie nazi por las fotografías de los campos de concentración, el Titanic por el filme de James Cameron, y la crueldad de la guerra por Peckinpah-. Todo recuerdo inmemorial y la mayoría de los acontecimientos históricos -en los cuales no estuvimos presentes-, requieren de asociaciones gráficas que nos permitan evocarlos, que los alejen de las nebulosas de lo abstracto y los hagan más tangibles en nuestro pensar.

En el ámbito cotidiano los espacios públicos testigos de hechos históricos actúan como su metáfora viva en el sentido dado por Ricoeur

\footnotetext{
1 En referencia a la famosa fotografía El hombre frente al tanque de Charlie Cole, ganadora del World Press Photo of the Year de 1990.

2 Hasta el punto, como bien sabemos, que se las conoce como las Madres de Plaza de Mayo. Se trata de un referente paradigmático de apropiación discursiva de un espacio público, convirtiendo el fondo político de las reivindicaciones de las Madres y el espacio Plaza de Mayo en sinónimos.
} 
(2011). Las reivindicaciones populares, como performance, añaden episodios narrativos a los espacios públicos, muchos de los cuales aspiran a permanecer inalterados ad aeternum -precisamente por su trascendencia histórica, urbana, institucional, cotidiana- y en la ordenación del urbanismo público. Se convierten así en iconos conmemorativos, cargados de valor metafórico, simbólico e identitario -pensemos en la importancia simbólica y transversal que la fuente de Cibeles tiene para miles de personas de todo el mundo, pensemos en la Meca, en el Muro de las Lamentaciones, en el Camino, los arcos del triunfo, el Monumento a Lincoln de Washington D.C., la isla de la Libertad, espacios-coordenadas de peregrinación-. Mientras estos iconos permanezcan en pie, seguirá existiendo en el imaginario colectivo un espacio ritual, un símbolo consagrado a su evocación. Decía Althusser que "la conciencia existe en prácticas materiales y rituales estructuradas" (Larraín 2008: 140). Por ende, la permanencia física del espacio concreto determina la supervivencia de la idea política -0 , cuando menos, su actualidad- ${ }^{3}$ Como apunta Mouffe, "los espacios públicos son siempre estriados y se estructuran hegemónicamente" (2014: 98). El espacio está dotado de su propio texto hegemónico -y, por supuesto, potencialmente contrahegemónico-, y el recuerdo de los acontecimientos, física y sensitivamente fijados como marcos interpretativos de contextualización, de un poder de evocación que permite su subsistencia discursiva y su capacidad de constante interpelación.

Ahora bien, ¿nos referimos a todo tipo de espacio, sin establecer una mayor especificación? Si observamos las evidencias pictográficas y fotográficas de las principales conquistas políticas y sociales del último siglo, comprobamos que la práctica totalidad de sus representaciones gráficas rebela la existencia de los componentes espacial y público, hecho que contrasta con la dificultad de evidenciar gráficamente los hitos políticos obtenidos en el ámbito privado. Según Bobbio, con relación a la dicotomía público-privado, la esfera privada se desenvuelve "de puertas hacia adentro del ámbito doméstico y familiar, es la esfera de nuestros pecados inconfesables" (2013:

3.- A modo de ejemplo, pensemos en el estado actual del espacio que en 1945 alojó el búnker de Hitler -convertido hoy en un aparcamiento público-, en la caída del Muro de Berlín como constatación del colapso soviético, o en la destrucción de las ruinas de Palmira por parte de Daesh. Es tristemente común oír la expresión reducir a cenizas como símil de destrucción total. 
75). Mientras, "la esfera pública es aquella en la cual relucen o se ostentan hipócritamente nuestras flacas virtudes, y advierte que solo en la tiranía lo público y lo privado coinciden." 4

Recordemos que en la época clásica las calles ${ }^{5}$-el espacio público eran la quintaesencia fenomenológica de la vida en sociedad, de lo común, el escenario de representación de toda posibilidad social y política. Las calles no solo servían de meros conectores urbanísticos, sino como nexos espaciales de dinamización del desarrollo social y económico de las ciudades. Desde la psicología moderna, el espacio público es aquel "terreno común donde las personas llevan a cabo las actividades funcionales y rituales que unen a una comunidad" (Carr, et al. 1992: 6). Todo ello, "dentro de un marco ideológico de libertad y diversidad limitados, tanto por variables de seguridad como por imperativos culturales de orden y decoro moral" (Dixon, et al. 2006: 187). Precisamente, por ser espacios de propiedad simultánea de todos y de ninguno, son susceptibles de apropiación. Es en el espacio público,

Donde se busca revertir una situación de necesidad o privación, una opción política antagónica o un modo no reglado de recrear vínculos de sociabilidad, en un juego de confrontación entre públicos y contra-públicos que reproducen o desafían la concepción dominante de las relaciones sociales (Mitchell 1995).

Posiblemente, la principal virtud del espacio público sea su visibilidad término que podemos contrastar, por ejemplo, con las denominadas políticas de invisibilidad, o los conceptos de subgobierno y criptogobierno de Bobbio-. Recordemos que, para los clásicos, el foro era el espacio político por excelencia: entendían que, si efectivamente la cosa pública era común, ello debía evidenciarse en el espacio común y a la luz del día. De ahí la importancia

\footnotetext{
4.- Mitchell, Don (1995). "The end of public space? People's park, definitions of the public, and democracy", en Annals of the Association of American Geographers, Vol. 85, No. 1, marzo, p. 116: Public space occupies and important ideological position in democratic societies.

5.- Sobre el concepto de espacio público, véase Berroeta, Héctor y Tomeu Vidal Moranta (2012). "La noción de espacio público y la configuración de la ciudad: fundamentos para los relatos de pérdida, civilidad y disputa", en Polis, Revista Latinoamericana, No. 31, pp. 9-10: el espacio público corresponde al marco mediático en el que se presentan al público los distintos contenidos de la vida social [...].
} 
simbólica y metafórica -prácticamente exclusiva, ya que existen notables excepciones de espacios privados testigos de importantes hitos sociopolíticos, los cuales, no obstante, por motivos de propiedad, accesibilidad y dimensiones, dificultan el concurso de performances políticos de mayor significación colectiva-, del espacio público que, por su propia naturaleza, es visible y lúcido, abierto, estratégico e histórico, y, aún siendo común, apropiable.

\section{¡Tomar las calles!: movilización popular e indignación.}

Apropiarse del espacio público conlleva, pues, la disputa contingente por el control de un terreno físico como símbolo de expresión performativa del fenómeno político. Como expresión, tomar las calles posee un sentido dual: por un lado, tomar las calles físicamente implica movilizarse, concurrir en ellas, incluso detener la normalidad urbana -lo cual no debe confundirse con vandalismo ni conductas violentas-, incursionar en la hegemonía de los espacios; por otro lado, tomar las calles en sentido simbólico significa apropiarse discursivamente de las connotaciones -gráficas, mediáticas, identitarias, representativas, institucionales, metafóricas- del espacio público, como soporte físico coyuntural de un determinado reclamo popular. Tomar las calles implica la fundación de una praxis de significación colectiva, de una comunión, incluso, como sostengo en otro trabajo ${ }^{6}$, en el sentido de la koinonía.

Las victorias políticas que se obtienen y celebran en entornos cerrados -sedes partidarias, despachos privados, sala de juntas de las cúpulas partidarias-son, en realidad, las victorias de unas pocas personas, de las élites de las tiendas electorales -las victorias clásicas de la política de reservados y hoteles de lujo, de secretismo y oscurantismo-. Bobbio decía que el soberano -figura que, en este punto, bien podemos asimilar con "quienes nos gobiernan y los agentes políticos- pretende ser, al igual que Dios en el cielo, omnividente e invisible a la vez, [...] siendo omnipotente precisamente porque es el omnividente invisible" (2016: 41). Efectivamente, las calles,

6. Cfr. De Domingo, Carlos (2019f). "Ecuador a.C. - Ecuador d.C.: una lectura mesiánica del correísmo". Inédito al momento de escribir estas líneas. 
y lo que estas conllevan para el discurso político, forman parte de la carga genética de cualquier noción de democracia, hasta el punto de que nos resulta extremadamente arduo argumentar la existencia o inexistencia de una noción estandarizada de democracia sin evaluar las posibilidades reivindicativas una vez más, no-violentas- de las calles.

Por el contrario, las victorias -en mayor medida- obtenidas en espacios públicos, son inclusivas, abiertas a la colectividad, ya que a priori permiten una participación abierta y no segregada. Así, el discurso político penetra en la concepción social que, sobre una concreta ubicación física -en la cual los individuos despliegan su cotidianeidad-, mantiene la ciudadanía. Aplicando al plano físico la teoría de la performatividad de Austin, ocupar el espacio público supone la imposición en dicho espacio de nuestros cuerpos, de nuestra presencia como significante político.

Dicha presencia no solo implica el concurso de materia, de nuestra corporalidad como hecho performativo -recordemos que, según Eco, el derecho a pensar forma parte de los derechos de la corporalidad-. Los cuerpos también añaden elementos tangibles, sensitivos y gráficos al performance político, como fuente y medios afectivos de los valores (Ricoeur, 1950). En palabras de Foucault, el cuerpo es "el lugar de inscripción de los sucesos". Husserl, por su parte, afirmó que "el cuerpo propio tiene la función de punto de partida de toda praxis" (Walton 2014: 239). Estar presentes en un escenario físico, por lo tanto, no solo refiere un espacio concreto a la expresión política, sino a su misma potencia. Se abre una puerta a su realización performativa, a su expansión orgánica, a su materialización contingente.

Recordemos brevemente a los indignados españoles del 15-M. Los indignados no solo fueron un conjunto de individuos descontentos, con determinadas inquietudes políticas y protestas sociales, una multitud de cuerpos. Éstos no se limitaron al momento puntual de la indignación. Sus cuerpos, más bien, fueron la potencialidad de una revolución, la potencia expansiva de la indignación, de un contagio orgánico. Con sus protestas, los indignados hicieron físico un reclamo político abstracto -específico, a fin de cuentas, pero basado en lo ontológico, en lo intangible-. Igualmente, entre 2015 y 2017 la ciudadanía ecuatoriana hizo presencia física, en las 
calles, la fricción popular que asolaba a una sociedad polarizada entre dos opciones políticas, ambas revestidas de una clara carga ética y axiológica en el marco discursivo y de la opinión pública. Del mismo modo, saliendo a las calles, la ciudadanía afecta al correísmo y a la oposición desplegaron con su corporalidad el performance de un pensamiento político, poniéndole rostros, apellidos y nombres a nociones tan abstractas como ciudadanía o comunidad, demostrando su disposición a la apologética dialéctica de sus convicciones.

Ahora bien, ¿a qué se debe la diferencia entre las movilizaciones populares de 2015 y 2017 y el proselitismo político de 2019 -en cuanto a la cantidad de reclamos, su convocatoria y su precisión discursiva-? Más allá de conciertos y demás propuestas de ocio -sin valor político, únicamente comercial-, ¿asistimos en 2019 a actos realmente multitudinarios en apoyo a los candidatos a la Alcaldía de Quito? ¿Observamos algún tipo de contagio orgánico, por minúsculo que fuera, que hiciera que el electorado indeciso se movilizara en pos de una opción política concreta? Concretamente, ¿acaso no persigue toda movilización política que sus mensajes, propuestas y protestas rebasen la frontera limitada de lo físico -del aquí, del ahora, de lo que podemos tocar- $\mathrm{y}$ se difuminen en el aire del medio social?

\section{(Des)movilización y protesta ciudadana del Ecuador d.C. A 2019.}

Obviamente, el Ecuador no es Grecia, ni España. Tampoco Egipto o Estados Unidos. Como bien sabemos, no existe ningún determinismo según el cual, dándose fórmulas reivindicativas equivalentes y similares herramientas de comunicación, éstas deban funcionar de forma idéntica en entornos dispares -mucho le costó al marxismo reconocerlo, incluso en entornos que podían considerarse parecidos-, ni siquiera en una misma comunidad política. Por ejemplo, antes de la irrupción del correísmo, el Ecuador era una nación récord en defenestrar presidentes y gobiernos, recuerdo que el pueblo ecuatoriano atesoraba -y sigue atesorando- con un gran poder evocatorio - pero, como podemos observar hasta ahora, ninguna garantía de réplica por la vía pacífica-.

Convengamos que el punto álgido de las protestas populares contra el régimen de Correa Delgado tuvo lugar en la Tribuna de los Shyris en junio de 
2015. El relato del segmento opositor, según he podido conocer, es prácticamente unánime: las multitudinarias protestas de los Shyris bien pudieron haber derrocado al aparato correísta -entendido como hegemónico, incluso, según algunos colegas, como Estado total (Schmitt 2017: 55)- de no haber mediado la visita pontificia de Francisco - del 5 al 8 de julio-. Sin embargo, ¿por qué estaban tan seguros de ello?, ¿qué recuerdos y evocaciones sobrevolaron las protestas de los Shyris y las mentes de los ciudadanos de oposición?

Antes de Correa Delgado, la sociedad quiteña se vanagloriaba de botar presidentes, al haber logrado derrocar gobiernos tan discutidos como los de Bucaram, Mahuad y Gutiérrez. Estas hazañas reivindicativas aún estaban presentes en el imaginario colectivo -y en la configuración histórica ecuatoriana- al momento de las protestas de los Shyris -las cuales, como podemos comprobar, poco han tardado en reaparecer durante las revueltas contra el gobierno de Moreno Garcés, sea que las consideremos políticas o, en el sentido dado por Žižek, ultrapolíticas (2007: 29)-. Concretamente, la potencialidad de estas protestas era y es vislumbrada bajo el prisma romántico -ciertamente naif- del recuerdo de aquellas reivindicaciones exitosas. En 2015, la esperanza potencial de derrocar al gobierno correísta en las calles procedía, por tanto, de la reminiscencia histórica de gestas pasadas, lo cual también hemos podido observar en las revueltas y la marcha indígena de octubre de 2019. Como oí decir a algunos colegas ecuatorianos durante las protestas de 2015, y últimamente he vuelto a oír en la conversación pública: si ya lo hicimos antes, ¿por qué no ahora?

De forma general, las diferencias entre las marchas previas al correísmo y las protestas opositoras de los Shyris son más que evidentes -con respecto a la Revolución de los Zánganos de 2019, denominada así por el polo correísta, creo prudente no emitir ninguna valoración, aún asentada en hechos contrastados y concordancias teóricas, por considerarla extraña al marco temporal aquí estudiado y, sobre todo, por la dificultad añadida de abordarla historiográficamente, debido a su actual efervescencia, y objetivamente, desatendiendo el prisma ideológico - . Las protestas contra Bucaram, Mahuad y Gutiérrez fueron predominantemente transversales. Se erigieron como fruto de la constitución efectiva de un bloque histórico contra un enemigo común, como la reacción popular contra una gestión de la cosa pública calificada 
como nefasta y de los abusos sistemáticos de la clase política. En este sentido, considero que los gobiernos de Bucaram, Mahuad y Gutiérrez fueron postideológicos -ya que, más allá del discurso no hicieron gala de una ideología clara y precisa-, sino que nadaban en la ambigüedad del oportunismo y la supervivencia, siendo precisamente la inexistencia de un componente ideológico definido el detonante que posibilitó la conformación de un bloque histórico, bloc soreliano exento de la primera fase de su configuración, posiblemente la fase más crítica: la obtención de un consenso mínimo entre los distintos agentes sociales y políticos integrados en el bloc, mismo que, tras desplazar momentáneamente las tensiones ad intra y siguiendo la famosa sentencia de Freud ${ }^{7}$, identifica ad extra al enemigo común. Dejando de lado las cuestiones puramente políticas e ideológicas, las contingencias contra una alineación colectiva eficaz, conformada frente a un enemigo común, suelen resultar inocuas y poco fructíferas (Laclau y Mouffe 2015).

Si los regímenes del Ecuador a.C. -antes de Correa- fueron postideológicos, el régimen correísta no solo fue profundamente ideológico -en sentido neutro gramsciano-, sino ilusionante. Estructurado, allá por 2007, como movimiento recolector de la cadena de equivalencias anticapitalista y socialista, Alianza PAIS hizo de paraguas para un sinnúmero de movimientos sociales, captando estratégicamente a sus líderes -sus propuestas y sus discursos-, desarticulando toda pulsión política externa, monopolizando los espacios públicos -desde la Academia, hasta la judicatura, los gremios profesionales, la cultura, etc.-. Ello provocó que, frente a eventuales escisiones, los movimientos sociales menguaran progresivamente, perdiendo activos -que decidieron permanecer en la comodidad del oficialismo-, propuestas y proyectos en beneficio del régimen. Como resultado, las cabezas pensantes o, al menos, las más visibles, de los distintos movimientos fueron transferidas al Gobierno -descabezando los movimientos-, dificultando posteriores expresiones reivindicativas.

Aunque el desencadenante de las protestas de junio de 2015 fue de índole tributario, el factor ideológico estuvo muy presente. ¿No aprendimos

7.- "Es posible ligar en el amor a una multitud mayor de seres humanos, con tal que otros queden afuera para manifestarles la agresión". Cfr. Freud, Sigmund (2010). El malestar en la cultura. Madrid: Alianza, p. 111. 
de las revoluciones de 1775 y 1789 que la cuestión tributaria es un despertador reactivo de la conciencia política? Más que como un ajuste tributario, los gravámenes propuestos por la Presidencia de la República fueron leídos mediante la moralización de la política descrita por Mouffe -resultando, así, la dicotomía bien/mal, moral/inmoral-. Si los gobiernos de Bucaram, Mahuad y Gutiérrez, como sostengo, no fueron ideológicos, la línea de fidelidad ciudadana operó en consecuencia, emanando del beneficio directo, de las redes clientelares y los presuntos negociados. No se trataba de una afinidad ideológica o una identificación política o moral. La aprobación de estos gobiernos no se deslizaba desde el marco de la identificación ciudadanía/régimen, sino desde el hecho de ser Incluido o Excluido del mecanismo estatal (Žižek 2009: 119). Sin embargo, cuando las diferencias son ideológicas -para lo cual, indefectiblemente, tiene que haber una labor discursiva, lo cual no se dio en las Elecciones Seccionales de 2019, con la excepción del movimiento correísta-, tanto más difícil es conformar un bloc o una cadena de equivalencias.

Según considero, la efectividad de las calles como medida pacífica de presión frente al régimen, en el contexto ecuatoriano, mermó considerablemente, fruto de la confianza ciega que emanaba del recuerdo de la idiosincrasia quiteña de botar presidentes, manteniéndose cierta creencia determinista como respaldo de esta idea - producto de los casos de éxito de las protestas cívicas acontecidos alrededor del orbe durante los últimos años- ${ }^{8}$ Hay unanimidad en que en las últimas grandes protestas sociales - caso egipcio, tunecino, español, griego, estadounidense, francés, etc.- la importancia de las redes sociales como herramienta de comunicación, información y organización fue indispensable ${ }^{9}$.

Ahora bien, no vamos a profundizar aquí en las cualidades específicas

8.- Por ejemplo, ¿por qué en Grecia el movimiento de plazas fue un éxito, y en el Ecuador no se logró emular ninguna alternativa viable? Véase Katsambekis, Giorgos (2015). "El ascenso de la izquierda radical griega al poder. Notas sobre el discurso y la estrategia de Syriza", en Línea Sur 9, pp. 165-174.

9.- Véase Soengas, Xosé (2013). "El papel de Internet y de las redes sociales en las revueltas árabes: una alternativa a la censura de la prensa oficial", en Comunicar, No. 41, Vol. XXI, Revista Científica de Educomunicación, pp. 147-155; Katsambekis (2015): passim; Cfr. Gendler, Martín, et al. (2015). “Tecnologías digitales y activismo político: ¿un encuentro indispensable?”, en XXX Congreso de la Asociación Latinoamericana de Sociología, Universidad de Costa Rica, pp. 2-6; Romanos, Eduardo (2016). "De Tahrir a Wall Street por la Puerta del Sol: la difusión trasnacional de los movimientos sociales en perspectiva comparada", en Reis, Revista Española de Investigaciones Sociológicas, No. 154, abril-junio, pp. 103-118; Véase Scherman, Andrés, et al. (2013). "La protesta en la era de las redes sociales: el caso chileno". En Intermedios. Medios de comunicación y democracia en Chile. Arturo Arriaga y Patricio Navia: pp. 181-199. Santiago: Ediciones Universidad Diego Portales. 
que posibilitaron el éxito de dichas protestas -cuyo caso paradigmático más moderno es el de los chalecos amarillos contra el gobierno de Macron-, únicamente en las particularidades del caso ecuatoriano, enfocadas, sobre todo, al uso de las redes sociales por parte de las tiendas partidarias - contribuyendo a la generación de la militancia de chat y sus productos de infoxicación y comunicación muerta, carente de contenidos ${ }^{10}-$. Pese a su lógico régimen de diferencias, los ejemplos revolucionarios o reivindicativos que hemos mencionado enfrentaron un conjunto de elementos apriorísticamente comunes, tales como la utilización autoritaria del poder estatal, la marginalidad política e institucional de la oposición, el control de los poderes por el ejecutivo, cargas policiales, criminalización de la protesta, limitación de los espacios públicos, etc. También caben muy diversas lecturas de por qué el reclamo pacífico popular -la gente en las calles- funcionó exitosamente en unos contextos y en otros resultó un fracaso -como, según sostengo, fue el caso ecuatoriano entre 2015 y 2017-. Veamos, sucintamente, los motivos de la desmovilización ciudadana en las calles, proceso que trajo consigo la aparición de lo que denomino militancia de chat-como nuevo paradigma de participación política-, y que se dejó ver en la disminución de la presencia proselitista de los militantes y simpatizantes partidarios durante las Elecciones Seccionales de 2019.

\section{Crisis partidaria y militancia de chat}

En primer lugar, considero que la desmovilización del segmento opositor anterior a 2017 fue paulatina. En efecto, se reconoce un punto de inflexión -y álgido- en las protestas de los Shyris de junio de 2015, decayendo desde ahí la movilización en cuanto a presencia física y discursiva-propositiva y poder de convocatoria -mostrándose, una vez más, que la ciudadanía, en su organicidad transversal, posee un poder de autoconvocatoria superior al de la mayoría de los agentes partidarios--. En contra de esta afirmación, bien puede

10.- Entendida la comunicación, en este punto, como símil del fetichismo de la mercancía marxista, concepto que describe cuando el curso productivo se recrea en sí mismo, sucediéndose de forma desbocada. Walter Benjamin hablaría de la repetición inercial de unos medios sin un fin plausible. Algo parecido a la noción de condensación de Todorov (1997), estado en el que el significado es más abundante que el significante. 
acudirse, como suelen hacer algunos distinguidos colegas, al argumento del control estatal de los medios de comunicación, hecho justificativo de la pobre concepción social sobre los performances reivindicativos de oposición. Sin embargo, y aquí me permito un conciso juicio de valor, la desmovilización es mérito propio de los agentes políticos y de sus tiendas partidarias, de su comportamiento autosuficiente y endiosado, y de la escasa consideración hacia las bases, reconvertidas en fuerza de choque, en cuerpos para la protesta, en una masa indeterminada e impersonal. ${ }^{11}$

Desembocamos, así, en una crisis de representación, en la que el electorado vota desapasionadamente, por inercia, por imperativo legal o por necesidad -castigo, cambio, necesidades económicas, laborales, etc.-, pero nunca por razones de identificación moral con los candidatos -que es, según sostiene Lakoff, lo que mueve al electorado, más que el interés-.

El mejor análisis de la crisis partidaria -de representación e incluso, como sostengo en otro texto ${ }^{12}$, orgánica- que asola al Ecuador la realizó, hace más de un siglo Moisei Ostrogorski, quien alertó del marcado carácter antidemocrático de los partidos políticos cuando son sus miembros quienes, sirviéndose de lo que denominó maquinarias electorales, alcanzan la satisfacción de sus propios intereses particulares (Sorel 2014: 57). Encontramos, pues, una lectura de los partidos políticos como organizaciones cupulocráticas (De Diego 2008), que pregonan, como aludía Walter Benjamin, la confianza ciega en el partido, convirtiendo el partido como fin en sí mismo (Löwy 2003). Muy pocos, después de vivir las dinámicas partidarias internas -o haber trabajado en/para ellos-, acaban defendiendo una idea benévola y naive de las tiendas políticas.

11.-Véase Cohn-Bendit, Daniel (2013). ¿iContra los partidos políticos!? Madrid: Catarata: un partido [político] es como un escudo, una estructura cerrada y casi genéticamente hermética a la sociedad; y De Diego, Enrique (2008). Casta parasitaria. La Transición como desastre nacional. Barcelona: Rambla, passim. Los bajísimos índices de afiliación partidaria en el Ecuador dan buena cuenta de la paupérrima consideración que hacia los movimientos y partidos políticos posee la ciudadanía ecuatoriana. Lejos queda, pues, la relación pura a la que se refería Giddens, aquella en la que uno entra y permanece por su propia voluntad, debido a la gratificación que proporciona la asociación con otros (Mouffe, 2011: 53).

12.-Cfr. De Domingo, Carlos (2019e). "Dos Ecuadores: antagonismo, conflicto y Gramsci en la mitad del mundo". Inédito al momento de escribir estas líneas. En este texto sostengo, grosso modo, que la polarización popular producto de la época correísta es, salvando las distancias, similar al fenómeno histórico de las dos Españas, ya que, al hablar del Ecuador, opositores y correístas hablan de países y realidades nacionales distintas, erradicando toda intersubjetividad sobre los acontecimientos de la Década Correísta y generando fricciones pre-bélicas entre la ciudadanía. 
También gozó de un papel protagónico en la desmovilización la falta de acuerdos entre los distintos agentes opositores, que terminaron fragmentando a un colectivo ya de por sí marginal en sentido hegemónico, opacándolo y opacándose entre sí. Así lo alertaron en los comicios de 2019 quienes, con la intención de generar un cordón sanitario alrededor del actual alcalde Jorge Yunda y Luisa Maldonado, pidieron el acercamiento entre las candidaturas de César Montúfar, Juan Carlos Holguín y Juan Carlos Solines.

Según he podido observar durante los últimos años, el exceso cuantitativo de marchas y plantones, como forma de protesta pacífica, acaba siendo contraproducente. Configurándose como meras réplicas cíclicas, y sin poseer una entidad unitaria definida que permita la fácil adhesión popular, se instaló en el contexto ecuatoriano, como costumbre reaccionaria, la protesta desprogramada -ignorando el paso de la cantidad a la calidad (Piaget 1972). A pesar del clima de fricción que vivió el pueblo ecuatoriano durante la última década, la abusiva y cíclica aplicación de fórmulas idénticas sumió a la ciudadanía en la insulsa monotonía, deslegitimando, con esta deficiencia performativa, el fondo ideológico -aún siendo perfectamente válido- y los distintos liderazgos políticos. Las calles, como medida de presión, no responden a lógicas acumulativas. Las calles, por sí solas -sin alcanzar ningún grado o conato de violencia-, poseen una eficacia directamente proporcional a la fuerza de resistencia del régimen que enfrentan -generalmente, más violentas que pacíficas, estableciendo una clara línea divisoria entre las labores legales de antidisturbios y la represión de manifestantes no-violentos-. Al contrario de la simple acumulación, las protestas encuentran su punto de fuga en la intensidad progresiva y en el timing simbiótico - sincronizado- de un conjunto estructurado, conexo o no, de acciones equivalentes. Así lo explican Laclau y Mouffe, partiendo del pensamiento de Bernstein:

Los avances democráticos no son acumulativos, dependen de una relación de fuerzas que es imposible determinar a priori, [...] la lucha no es simplemente un combate por avances localizados, sino por formas de articulación de fuerzas que permitan consolidar esos avances que son siempre reversibles (2015: 68). 
Los avances sociales alcanzados sectorialmente no son, pues, materialmente acumulables entre sí. Echando la vista atrás, observamos que la sectorialización de las protestas durante el correísmo no solo no contribuyó al éxito individual de éstas, sino que dinamitó todo progreso orgánico -desperdiciando las oportunidades que ofrecen, tanto en la teoría como en la práctica, el bloc y la cadena de equivalencias--. Cada gremio se limitó a marchar por la defensa de sus propios intereses. ${ }^{13} \mathrm{Y}$, consecuentemente, cada tienda política hizo lo propio, errando ostensiblemente a la hora de conjugar el espontaneísmo propuesto por Rosa Luxemburgo, siendo incapaz de estructurarse como unidad simbólica.

Las redes sociales son utilísimas herramientas de información, de divulgación de hechos y eventos -gracias a su rápida difusión-, también de motivación - gracias a la difusión viral de contenidos multimedia de efectos efervescentes y de enaltecimiento identitario y patriótico-, incluso de organización multitudinaria. Convengamos, pues, que hoy en día las redes sociales son impostergables, inevitables y omnipresentes ${ }^{14}$, y como tales, una parte desmedida de la política óntica se ha volcado en ellas. Sin embargo, la utilización excesiva de las redes sociales -cuyo principal uso no es político, sino personal-, diluye los contenidos netamente políticos.

En palabras de Baudrillard, refiriéndose a la comunicación contemporánea, vivimos en la monotonía debido al exceso de sentido, de información y visibilidad, del éxtasis [obsceno] de la comunicación. Siguiendo con el crítico francés:

13.-Véanse, por ejemplo, las distintas marchas indígenas de la CONAIE, la CONFENIAE y la ECUARUNARI, así como las marchas de los Saraguro, los comuneros de Tundayme o la Marcha del Agua, las marchas obreras organizadas por el Frente Unitario de Trabajadores, las marchas de educadores y profesores respaldadas por el Movimiento Popular Democrático, las protestas de los médicos en apoyo al cirujano Carlos López, respaldadas por la Federación Médica Ecuatoriana y el Colegio Médico de Pichincha, las marchas de los pensionistas del ISSFA y del ISSPOL, etc. Pongamos, como contrapeso -salvando las distancias- las mareas españolas, que en un primer momento fueron subsumidas por el partido político Podemos acorde a la teoría postmarxista de la cadena de equivalencias.

14.- Según la Encuesta de Tecnologías de la Información y Comunicación 2017 del Instituto Nacional de Estadística y Censo, el 58,5\% del total poblacional del Ecuador posee celular activado, del cual el 63,3\% son smartphones. De ahí, el 31,9\% utiliza redes sociales desde smartphone, siendo WhatsApp y Facebook las aplicaciones más descargadas en el Ecuador. * Consúltese el enlace: www.metroecuador.com.ec/ec/tecnologia/2018/01/15/aplicaciones-ecuador.html. [Fecha de consulta: 6 de junio de 2019]. 
La promiscuidad imperante sobre las redes de la comunicación es la de una saturación superficial, una solicitación incesante, un exterminio de los espacios intersticiales. [...] Las masas se sumen en la indiferencia extasiada, en la pornografía de la información. ¿Si el universo moderno de la comunicación, de la hipercomunicación, nos hubiera sumido no en lo insensato, sino en una enorme saturación de sentido? [...] ¿Si la información no remitiera ya a un acontecimiento, sino a la promoción de la propia información como acontecimiento? (2001: 72-3).

El exceso de estímulos informativos genera la famosa infoxicación propuesta por Toffler. Ciertamente, el homo videns de Sartori ha dado paso al homo smartphonicus, ese ser postmoderno que entiende la telefonía móvil como la prolongación de sus extremidades superiores. No queremos entrar aquí en el debate entre la consideración de las redes sociales como expresiones periodísticas espontáneas y populares -que, de pronto, pueden generar casos de post-verdad y fake news- y la ausencia del criterio periodístico en la "información" en ellas vertidas. En un medio en que un meme es más consumido -y en menos tiempo, ya que nuestras vidas son dinámicas, en constante movimiento- que una noticia contrastada o un producto audiovisual de más de minuto y medio, corremos el riesgo de ser sistemáticamente infoxicados. Como dijo Sartori, la televisión y el mundo de Internet invierten el progreso de lo sensible a lo inteligible y lo destruye mediante el retorno al puro y simple ver, producen imágenes y borran conceptos, atrofian nuestra capacidad de entender (2016: 19).

Partiendo de que la desinformación es un problema constante de las redes sociales, observemos cuál es el efecto que éstas han desplegado sobre la movilización ciudadana desde 2015 hasta la actualidad, incluyendo las Elecciones Seccionales de 2019.

Ciertamente, las redes sociales poseen utilidad como herramienta de convocatoria y comunicación de las líneas programáticas de los agentes políticos. En la actualidad, es impensable planificar una campaña electoral sin diseñar, dentro del departamento de comunicación, una estrategia para 
redes sociales. Para los individuos, acudir a las calles en circunstancias normales presenta dificultades, conlleva costos. Les resta tiempo -familiar, profesional, de ocio-. Deben desplazarse. Es molesto. Los individuos, aún los más reivindicativos, poseen escaso tiempo libre y responsabilidades que atender, están inmersos en dinámicas familiares con sus complejidades cotidianas. En resumen, los individuos tienen preocupaciones propias. Aún sabiéndolo, los agentes políticos piden -incluso exigen- compromiso, acompañamiento, contribuciones, asistencia a eventos de campaña, etc. Así las cosas, ¿cómo satisfacen los simpatizantes y militantes su necesidad de demostrar compromiso y responsabilidad política? Encontramos en este punto una lectura dual: o bien las redes sociales han causado la desmovilización de los individuos -es decir, los han sacado de las calles-, o bien han patrocinado el surgimiento de una nueva forma de movilización, exclusivamente digital y con apenas presencia física-performativa, la militancia de chat.

Este término está imbuido de la idea de que, con la aparición de las redes sociales, las bases militantes y los simpatizantes, así como los individuos en general, participan en el proselitismo político -del partido, del candidato, de su propia ideología- exclusivamente a través de canales de comunicación provistos por las redes sociales. Aún interesados en la discusión política, los individuos sienten efectiva su participación en redes sociales, como cumplimiento de un deber cívico y ético. Sin embargo, la militancia de chat se dedica a la difusión compulsiva de contenidos, irradiando información caótica. Mientras en Madrid, el Cairo, Túnez o París las redes sociales organizaron y congregaron a miles de activistas en torno a acciones reivindicativas, la presencia en las calles fue simétrica con el flujo de información digital. ¿Podemos decir lo mismo del caso ecuatoriano?

Recuerdo cómo en 2017 los agentes políticos reclamaban presencia en las calles, hegemonía del espacio, acciones visibles, tangibles y palpables, susceptibles de ser fotografiadas, filmadas y distribuidas mediáticamente. Olvidaron que no toda la militancia, lato sensu, puede realizar tal esfuerzo. En cambio, la movilización digital es mucho más sencilla, ya que requiere menos tiempo, no depende de limitaciones espaciales, y es prácticamente gratuita. Además, permite una confrontación simbólica, sin posibilidad aparente de violencia, más cómoda. La movilización digital no conlleva, 
per se, desmovilización. Lisa y llanamente, es otra forma de movilizarse y participar de la cosa pública.

La militancia de chat surge, pues, en un ambiente de descontento hacia los partidos y movimientos políticos, de un caldo de cultivo intergeneracional, de desconfianza medular y de desidia hacia el fenómeno político óntico. No es de extrañar, por tanto, que la militancia de chat no posea peso propositivo alguno - mucho menos decisional- en las prácticas del partido o movimiento político, aunque, a decir verdad, tampoco la propia militancia presentista posee ningún papel siquiera marginal en la confección y el debate programático.

El principal problema asoma cuando queremos considerar la existencia de las tensiones y pulsiones sociales y políticas en base a su visibilidad en las calles. El medio digital posee una visibilidad condicionada a su uso, a la permanencia de los sujetos en dicho medio -pese a que, literalmente, pasamos horas inmersos en redes sociales-. La no aparición de un hecho en el medio digital no implica su inexistencia, pero sí el eventual desconocimiento de su existencia. No trata tanto de la dicotomía existencia/inexistencia, sino de la percepción de ambas en el imaginario colectivo o su colocación en las distintas narrativas políticas. Como decía Foucault, la verdad está ligada circularmente a los sistemas de poder que la producen y mantienen (1979: 189). Esta afirmación tambalea todo sistema basado en la existencia o inexistencia de un evento, ya que, dialécticamente, toda afirmación está basada en la creencia en su verdad (Wittgenstein 2007). Lo dijo Pilato: ¿quid est veritas? A la postre, el nexo realidad-verdad que cada sujeto cree existente entre lo comunicado-lo acontecido depende de un ejercicio de confianza basada en una relación asimétrica de poder entre el emisor y el receptor o, como denomino en otro texto ${ }^{15}$, el Narrador y el suscriptor narrativo. En palabras del consultor hispano-ecuatoriano José Bernal,

No hay nada más subjetivo que la realidad, por cuanto en los ámbitos narrativo y discursivo podemos pasar de una única e inmutable realidad a

15.- Cfr. De Domingo, Carlos (2019f). "Ecuador a.C. - Ecuador d.C.: una lectura mesiánica del correísmo". Inédito al momento de escribir estas líneas. 
LAS CALLES: (DES)MOVILIZACIÓN CIUDADANA EN QUITO (2015 - 2019). UNA PERSPECTIVA COMPARADA DE LOS MOVIMIENTOS POPULARES DE INDIGNACIÓN.

una diversidad de realidades, que parten del hecho de ser contradictorias en si y entre sí, en base al reconocimiento intersubjetivo de que "realidad solo hay una", y, no pudiendo coexistir entre sí por excluyentes, deben negarse para confirmarse. ${ }^{16}$

Lo acontecido, para ser tenido como verdad indudable, debe evidenciarse, y el canal más común hoy día -rápido, accesible y asequible- para comprobar la existencia/inexistencia de un hecho es el digital. Como defienden algunos, un hecho no ha ocurrido a efectos mediáticos si no logra ser trending topic: perdemos, pues, toda información marginal al circuito digital hegemónico. ¿Acaso ello explica la importancia que los distintos movimientos políticos confirieron a las redes sociales, siendo más importante la difusión digital de sus performances en las calles que el fondo político de las calles y los actos performativos en sí mismos?

\section{Conclusiones}

Si comparamos la intensidad de las protestas contra el correísmo con los performances desarrollados durante el Ecuador a.C., que configuraron en el imaginario colectivo la idea de una ciudadanía combativa y capaz de botar presidentes, podemos observar notables diferencias en cuanto a la movilización popular, efectos también generados por la irrupción masiva de las redes sociales como herramientas comunicacionales. Pero, ¿podemos afirmar que las redes sociales son las únicas causantes del cambio de paradigma diferencial entre la movilización ciudadana durante las elecciones nacionales y seccionales del correísmo y las Elecciones Seccionales de 2019?

En mi opinión, una de las principales causas de la desmovilización callejera fue la excesiva reiteración de las calles como hecho performativo repetitivo, cíclico y monótono--, provocando tedio y hastío entre el electorado, en parte, tras comprobar, ya en 2019, la incapacidad de determinados candidatos por la Alcaldía de Quito en conformar un bloc soreliano contra

16.- Comunicación personal, del 10 de octubre de 2017. 
aquellas candidaturas que, a priori, no procedían del segmento de oposición al correísmo -por ejemplo, el pragmatismo discursivo de Jorge Yunda y su pasado oficialista, y la abiertamente correísta Luisa Maldonado-.

De cierta manera, la lucha en las calles ha sido considerada, tanto por la ciudadanía como por los agentes políticos, desde una perspectiva determinista, confiando en una lectura escueta y reduccionista de los fenómenos políticos y sociales que durante la última década han acontecido alrededor del orbe, y prescindiendo de la famosa advertencia de Bersntein bien secundada por Luxemburgo y Gramsci- de que la lucha democrática no es acumulativa - esto es, que ningún resultado positivo queda garantizado por la simple sumatoria de factores aleatorios, sino por la escalada in crescendo de factores contingentes equivalentes-. La lucha en las calles y la hegemonía del espacio se ven frenadas cuando, como es el caso quiteño, no existe un espacio definido con el suficiente poder evocatorio - ¿cuál podría ser, la Tribuna de los Shyris ${ }^{17}$, El Arbolito ${ }^{18}$, la entrada al recinto de la Asamblea Nacional, la Plaza de la Independencia, ...? Si tuviéramos que definir un espacio público concreto de Quito dotado del suficiente poder evocatorio como para causar expresiones dialécticas -tanto discursivas y gráficasmediáticas, como físicas, performativas y de ocupación pacífica- en aras de su apropiación simbólica y reivindicativa, ¿cuál sería? Es mi opinión, se trata de una pregunta tremendamente difícil de responder. Espero que el lector, con sus conocimientos y opiniones, sepa otorgarle algo de luz a esta cuestión.

Desde el lapso 2015-2017, cuando la fricción popular era palpable y la ciudadanía sufría una polarización muy superior a la que vivimos hasta los controvertidos hechos de octubre de 2019, la ciudadanía se ha venido sumiendo, progresivamente, en la desidia hacia los discursos políticos y

17.- Nótese que, como contraposición a la denominada Revolución de los Zánganos, un pequeño grupo de ciudadanos contrarios al paro de transportistas, la movilización indígena y los disturbios que trajeron consigo -sin poder afirmar o negar con total certeza si fueron directamente causados por estos o no-, se autoconvocó los días 8 y 9 de octubre en la Tribuna de los Shyris. Por lo que pude comprobar examinando los perfiles de sus precursores y difusores, el target ciudadano al que va dirigida se identifica con las marchas de oposición durante el correísmo.

18.- Del mismo modo, el punto de reunión de las distintas redes de la movilización indígena se celebró en El Arbolito, ubicación escogida por dicho movimiento para el asentamiento de las mujeres y niños indígenas llegados de los exteriores del Distrito Metropolitano de Quito. 
las promesas de campaña, menguando cada día más la confianza hacia la clase política y las organizaciones partidarias -lo cual responde a un fenómeno global y regional, de crisis de representación, si bien tampoco ayuda la correlación existente entre el aumento de la tasa de desempleo, la precarización económica-laboral y el número creciente de candidatos, dándose su máximo histórico en 2019-. Solo así podemos explicar lo anodinas que fueron las campañas por la Alcaldía de Quito y la Prefectura de Pichincha -la cual, debemos reconocer, fue mejor planeada por la candidatura correísta, aprovechando su histórica cercanía con el medio rural-.

Al contrario que Guayaquil, donde los socialcristianos gozan de una posición hegemónica, en Quito la continuidad y la fidelidad hacia las distintas tiendas políticas se ha revelado como meramente coyuntural, hecho que los propios candidatos a las distintas dignidades se han encargado de demostrar, pasando en su mayoría de un movimiento político a otro con respecto a su última participación electoral. Se trata de la prueba fehaciente de la escasa cultura partidaria que existe en el Ecuador, junto con el cambio compulsivo e interesado de las siglas, números y colores por parte de los candidatos en cada nueva cita electoral, la movilidad del voto -aún ideológicamente contradictoria-, hacia los distintos partidos -algo sorprendente a nivel globaly la ausencia de un verdadero sentido de pertenencia a las organizaciones políticas -lo cual se refleja en el bajísimo porcentaje de afiliación partidaria, mismo que no parece que vaya a reflotar en el futuro próximo-.

En definitiva, ¿qué democracia podemos esperar de los actuales movimientos y partidos políticos, cuando en ellos resulta notoria la ausencia de democracia interna y su capacidad para sintonizarse con el electorado es cada año más difusa y conflictiva? En un sistema de partidos como es el ecuatoriano - $\mathrm{y}$, debo reconocerlo, también el español-, corremos el riesgo de que las distintas nociones de democracia vengan determinadas por las organizaciones políticas y sus agentes ya que estos, como reflejos hipotéticos de la sociedad civil, articulan y desarticulan a placer conceptos y nociones tan esenciales para nuestra vida en comunidad. Si bien es cierto que llevamos años -y millones de dólares gastados- hablando de regeneración democrática -no solo en el Ecuador o América Latina, sino también en un buen número de naciones europeas-, lo cierto es que difícilmente podremos lograrla o 
alcanzar una mejora significativa si no se instauran mecanismos eficaces de control y verificación de democracia interna y participación en los partidos y movimientos políticos -como, en teoría, debería hacer España según establece la Ley Orgánica de Partidos-.

Es así, partiendo de la constatación de la desidia popular hacia la política óntica, que podemos ligar la paulatina desmovilización del electorado con la falta de credibilidad sistémica y el creciente tedio que generaron en el mismo las últimas Elecciones Seccionales de 2019 -en las cuales se contabilizaron casi 270.000 votos nulos o en blanco-, la incapacidad de crear blocs en aras de un objetivo común y la crisis de representación que Quito puede acabar sorteando con el Alcalde con menos votos que se recuerde, con poco más del $21 \%$. 
LAS CALLES: (DES)MOVILIZACIÓN CIUDADANA EN QUITO (2015 - 2019). UNA PERSPECTIVA COMPARADA DE LOS MOVIMIENTOS POPULARES DE INDIGNACIÓN.

\section{Bibliografía}

Baudrillard, Jean (2001). El otro por sí mismo. Barcelona: Anagrama.

Berroeta, Héctor y Tomeu Vidal Moranta (2012). "La noción de espacio público y la configuración de la ciudad: fundamentos para los relatos de pérdida, civilidad y disputa". Polis, Revista Latinoamericana, No. 31.

Berroeta, Héctor y María Isabel Muñoz (2013). "Usos y significados del espacio público en personas en situación de calle. Un estudio en Valparaíso y Viña del Mar”. Revista de Psicología de la Universidad de Chile, Vol. 22, No. 2.

Bobbio, Norberto (2013). Democracia y secreto. México D.F.: Fondo de Cultura Económica.

Carr, Stephen, et al. (1992). Public space. Inglaterra: Cambridge University Press.

Dixon, John, et al. (2006) "Locating impropriety: Street drinking, moral order, and the ideological dilemma of public space". Political Psychology, Vol. 21, No. 2.

Foucault, Michel (1979). Microfísica del poder. Madrid: Las Ediciones de las Piqueta.

Gramsci, Antonio (2005). Antología. [Selección, traducción y notas de Manuel Sacristán]. México D.F.: Siglo Veintiuno Editores.

Katsambekis, Giorgos (2015). "El ascenso de la izquierda radical griega al poder. Notas sobre el discurso y la estrategia de Syriza". Linea Sur, 9.

Laclau, Ernesto y Chantal Mouffe (2015). Hegemonia y estrategia socialista. Hacia una radicalización de la democracia. Buenos Aires: Fondo de Cultura Económica. 
Lakoff, George (2016). Política moral. Cómo piensan progresistas y conservadores. Madrid: Capitán Swing.

Lakoff, George (2019). No pienses en un elefante. Lenguaje y debate politico. Barcelona: Ediciones Península.

Larraín, Jorge (2008). El concepto de ideología. Vol. 2. El marxismo posterior a Marx: Gramsci y Althusser. Santiago: LOM Ediciones.

Mitchell, Don (1995). “The end of public space? People's park, definitions of the public, and democracy". Annals of the Association of American Geographers, Vol. 85, No. 1.

Mouffe, Chantal (2014). Agonística. Pensar el mundo políticamente. Buenos Aires: Fondo de Cultura Económica.

Proshansky, Harold, et al. (1983). "Place-identity: Physical world socialization of the self". Journal of Environmental Psychology Vol. 3., No. 1.

Ricoeur, Paul (2011). La metáfora viva. Madrid: Trotta.

Romanos, Eduardo (2016). "De Tahrir a Wall Street por la Puerta del Sol: la difusión trasnacional de los movimientos sociales en perspectiva comparada”. Reis, Revista Española de Investigaciones Sociológicas, No. 154, abril-junio.

Sartori, Giovanni (2002). Homo videns. La sociedad teledirigida. Barcelona: Taurus.

Sartori, Giovanni (2016). La carrera hacia ningún lugar. Barcelona: Taurus.

Soengas, Xosé (2013). "El papel de Internet y de las redes sociales en las revueltas árabes: una alternativa a la censura de la prensa oficial”. Comunicar, No. 41, Vol. XXI. 
LAS CALLES: (DES)MOVILIZACIÓN CIUDADANA EN QUITO (2015 - 2019). UNA PERSPECTIVA COMPARADA DE LOS MOVIMIENTOS POPULARES DE INDIGNACIÓN.

Walton, Roberto J. (2014). "Facetas de la corporalidad en la ética husserliana". Eidos, Revista de Filosofía de la Universidad del Norte, No. 21.

Wittgenstein, Ludwig (2007). Tractatus Logico-Philosophicus. Barcelona: Taurus.

Žižek, Slavoj (2007). En defensa de la intolerancia. Madrid: Sequitur.

Žižek, Slavoj (2016). La nueva lucha de clases. Los refugiados y el terror. Barcelona: Anagrama. 